\title{
Prediction of Tropical Cyclone Activity with Coarse Resolution Global Climate Models
}

\author{
$\underline{\text { A. Charles}},{ }^{\text {a b }}$, K. Shelton ${ }^{\mathrm{b}}$, T. Nakaegawa ${ }^{\mathrm{c}}$, H. Hendon ${ }^{\mathrm{b}}$ and Y. Kuleshov ${ }^{\mathrm{a}}$ \\ ${ }^{a}$ National Climate Centre, Bureau of Meteorology, Melbourne, Australia \\ ${ }^{b}$ Centre for Australian Weather and Climate Research, Bureau of Meteorology, Melbourne, Australia \\ ${ }^{c}$ Meteorological Research Institute, Japan Meteorological Agency, Tsukuba, Japan
}

Email: a.charles@bom.gov.au

\begin{abstract}
The generation of monthly to seasonal forecasts of tropical cyclone (TC) activity using physically based coupled ocean-atmosphere general circulation models (GCMs) has become feasible. GCMs not only simulate many of the large-scale processes that determine local favourability to cyclogenesis, but have also been shown to generate TC-like vortices and to reproduce key aspects of ENSO related variability in the spatial distribution of TCs.

In this study, seasonal TC predictions from two coupled ocean-atmosphere GCM based seasonal prediction systems are examined: the Japan Meteorological Agency/Meteorological Research Institute Coupled GCM (JMA/MRI-CGCM) and the Australian Bureau of Meteorology's (BoM) Predictive Ocean-Atmosphere Model for Australia (POAMA-M24). To evaluate the influence of model composition and tracking technique on seasonal TC predictions, two different TC tracking methods are applied to both models' hindcasts over the period 1981 to 2010. In the more traditional TC detection scheme, TCs are identified where sea level pressure is a minimum and the magnitude of 850 -hPa relative vorticity exceeds a certain threshold. A second TC detection scheme, developed at BoM for use with low-resolution climate models, uses the Okubo-Weiss-Zeta Parameter (OWZP), to identify regions with low-deformation flow and large amplitude vorticity. The schemes use warm-core criteria including moisture and wind shear thresholds and vertical structure criteria to eliminate cold-cored systems and ensure that only tropical disturbances in favourable environments are identified as TCs.

Both models and tracking schemes reproduce the inter-annual variations in the spatial pattern of TC genesis between El Niño and La Niña years. ENSO related variability which is reproduced includes 1) the northward shift of genesis location in El Niño years in the south-western Pacific, 2) increased TC genesis on the northern coast of Western Australia and in the eastern Indian ocean in La Niña years, and 3) increased genesis in El Niño years to the north of Madagascar. These results suggest that GCM-based forecasts of TC genesis will have skill for years in which ENSO has a strong influence on the pattern of cyclogenesis.

Relative vorticity at $850 \mathrm{hPa}$ and the 850 to $200 \mathrm{hPa}$ wind shear are important local environmental parameters affecting TC formation, and so the spatial pattern of predictability of these environmental fields is assessed over a hindcast period. Results indicate that model error remains a key limitation on potential forecast skill at seasonal timescales, with relatively low model skill at forecasting wind shear and vorticity north of Australia expected to limit the skill with which interannual variability in TC tracks can be forecast in this region.
\end{abstract}

Keywords: Seasonal forecasting, Tropical Cyclones, Global Climate Models 


\section{INTRODUCTION}

The spatial distribution of Tropical Cyclone (TC) activity in the Southern Hemisphere is modulated by largescale environmental drivers, the most significant of which is the El Niño Southern Oscillation (ENSO). ENSO's relationship with TC activity in the South Pacific is well documented (Diamond et al., 2013) (Dowdy et al., 2012) (Kuleshov et al., 2009). Links between the large scale environment and TC frequency have been known for some time (Watterson et al., 1995). In seeking to clarify the links between local large scale environment and cyclogenesis, Ramsay et al. (2008) found that zonal wind shear and relative vorticity were the most relevant local factors in the Australian region, with the interannual variability in these local factors driven by ENSOs modulation of the Australian monsoon trough and the South Pacific Convergence Zone.

The direct tracking of TCs in relatively coarse General Circulation Models (GCMs) for forecasting on seasonal timescales was first proposed over a decade ago (Vitart and Stockdale, 2001). In a recent comparison of statistical and dynamical seasonal predictions of TCs, Vitart et al. (2010) notes that while the tropical storms generated in GCMs lack features of real tropical storms such as an eye and rainbands, they share features such as lower level convergence, upper level divergence and high moisture content. They also noted that TC detection schemes developed for GCMs were effective when applied to atmospheric reanalyses.

Detection strategies have tended to follow the formula prescribed by Vitart et al. (2007) where TCs are identified by lower tropospheric relative vorticity maxima (minima in the Southern Hemisphere), with extra-tropical systems eliminated by the application of warm core threshold criteria. Vitart's scheme was tested on the ECMWF reanalysis using a vorticity magnitude threshold of $3.5 \times 10^{-6} \mathrm{~s}^{-1}$ and found to detect most actual TCs. In practice, when such schemes are applied to GCMs, the vorticity threshold is varied in order to account for model biases in different ocean basins and the effects of coarse model resolution. Other detection schemes have used wind speed thresholds for storm detection. Such thresholds have been shown to be highly dependent on model resolution (Walsh et al., 2007) (Murakami and Sugi, 2010).

In this paper we describe two dynamical seasonal forecasting systems and two TC tracking schemes, and demonstrate that all four combinations of models and tracking schemes are able to reproduce key aspects of the variability of TC genesis between different phases of ENSO. Following this, the predictive skill at seasonal timescales for the large scale environment in which TCs form is evaluated for wind shear and relative vorticity anomalies.

\section{SEASONAL FORECASTING SYSTEMS}

The operational Predictive Ocean-Atmosphere Model for Australia multi-week system (POAMA-M24) is described in detail in National Meteorological and Oceanographic Centre (2013). It comprises a T47 spectral atmospheric model with 17 vertical levels, coupled using the Ocean Atmosphere Sea Ice Soil (OASIS) coupler to an ocean model with 25 vertical levels, $2^{\circ}$ zonal resolution and $0.5^{\circ}$ meridional resolution at the equator increasing to $1.5^{\circ}$ near the poles. Land surface initial conditions are generated by a nudging scheme. An ensemble of 10 ocean and atmospheric states perturbed around a central analysis is generated using a coupled breeding scheme. The hindcasts (retrospective forecasts) are generated by three different configurations of the model with variations to flux correction schemes and shallow convection parameterisation.

The Japan Meteorological Agency (JMA) Meteorological Research Institute (MRI) Coupled GCM (JMA/MRI-CGCM) (Yasuda et al., 2007) is composed of the JMA atmospheric model running with a horizontal spectral resolution of T63 with 40 vertical levels, coupled to the MRI Community Ocean Model (MRI.COM) which is a z-coordinate ocean general circulation model with $1.0^{\circ}$ resolution in longitude and $0.3-1.0^{\circ}$ resolution in latitude and 50 vertical levels (24 levels in the upper $200 \mathrm{~m}$ ). Initial conditions are created using the Multivariate Ocean Variational Estimation (MOVE), a three-Dimensional Variational (3DVAR) method with coupled temperature-salinity empirical orthogonal function (EOF) modes. A flux correction scheme is applied to correct for biases in ocean-atmosphere energy exchange.

In this study TC tracks derived from the POAMA-M24 and JMA/MRI-CGCM hindcasts spanning the period 1981 to 2010, initialized on at the start of November each year are examined.

\section{TRACKING SCHEMES AND METHODS}

In this study we have compared two tracking schemes, a 'traditional' scheme described in Takaya et al. (2010) and a new scheme developed at the Bureau of Meteorology (Tory et al., 2013) called the 'Okubo-Weiss-Zeta Parameter' (OWZP) scheme. 
a) OBS
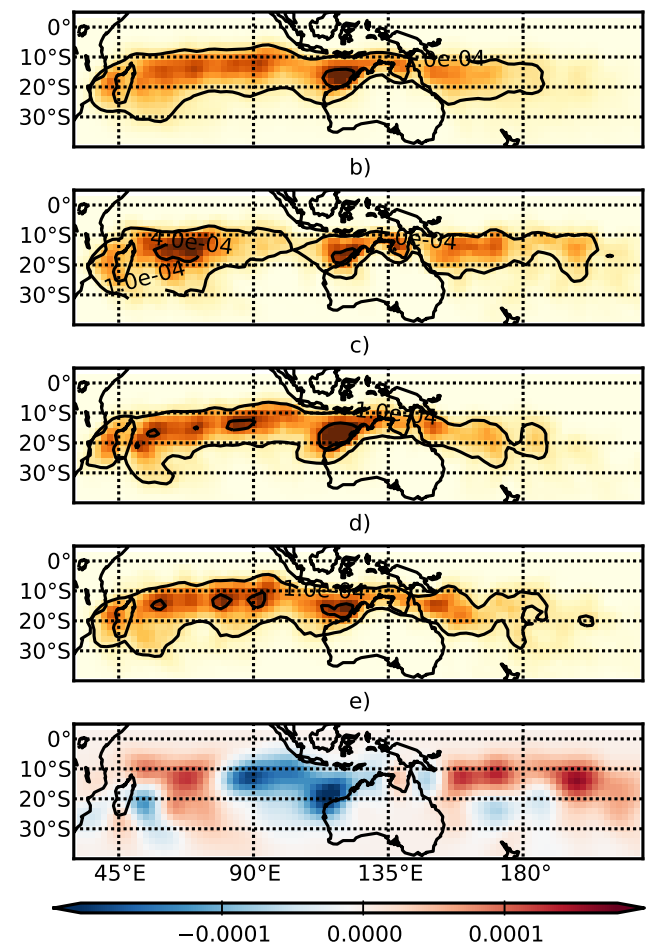

Figure 1. Tropical cyclone genesis densities for Southern Hemisphere best track data. The top four panels show normalised TC density for a) all , b) El Niño , c) La Nina and d) neutral years. The lower panel e) shows the difference between El Niño and La Niña years.

The traditional tracking methodology searches for sea-level pressure minima using a centred finite-difference scheme over a five by five stencil of neighbouring grid points, and applies a number of threshold-based criteria to classify the low as a tropical cyclone. For a TC to be declared at a sea level pressure minima, the cyclonic relative vorticity at $850 \mathrm{hPa}$ must exceed a threshold which was chosen to have magnitude $4.5 \times 10^{-5} \mathrm{~s}^{-1}$ for this study, for both models and for all regions. The warm core criteria is based on the difference between 200 and $500 \mathrm{hPa}$ geopotential height (Z200-Z500 thickness). The Z200-Z500 thickness must have a maxima close to the TC location, and is required to exceed that of the neighbouring 24 grid cells by $10 \mathrm{gpm}$ at this maxima. To exclude extra-tropical systems with a baroclinic vertical structure, a criteria whereby the wind speed at 200 $\mathrm{hPa}$ must be less than the wind speed at $850 \mathrm{hPa}$ at the TC centre is applied. Where a tropical cyclone has been declared in a previous time step, the structure and thickness criteria are ignored, and the vorticity threshold is relaxed. Thresholds must be exceeded for two consecutive days for a TC to be declared.

The OWZP is a measure of low deformation vorticity ('solid-body rotation'). In this scheme the OWZP must exceed certain thresholds at both $850 \mathrm{hPa}$ and $500 \mathrm{hPa}$ levels. The areal coverage of vertically coherent OWZP must exceed a certain size over ocean, lower tropospheric humidity thresholds must be exceeded in this area, vertical wind shear in this area must not exceed a certain threshold and the area must persist, meeting all other criteria, for at least 48 hours. If all criteria are met a TC is declared. Humidty and wind shear thresholds were determined by application of the tracking scheme to the ERA-40 atmospheric reanalysis. In this study relative and specific humidty thresholds at $850 \mathrm{hPa}$ of $70 \%$ and $12 \%$ were used, along with an 850 to $200 \mathrm{hPa}$ wind shear threshold of $12.5 \mathrm{~ms}^{-1}$.

Once TC tracks were generated for each model and tracking scheme, composites were created based on a decomposition of years into three phases: El Niño, La Niña and Neutral. The 'year', which corresponds to the Southern Hemisphere TC season, is defined as the period starting on November 1 and continuing to the end of April the following year. ENSO phase years were defined following based on the NOAA/CPC Oceanic Niño Index ${ }^{1}$. El Niño years are 1982, 1986, 1987, 1991, 1994, 1997, 2002, 2004, 2006 and 2009. La Niña years are

${ }_{1}^{1}$ published at http://www.cpc.ncep.noaa.gov/products/analysis_monitoring/ensostuff/ensoyears.shtml 
1983, 1984, 1988, 1995, 1998, 1999, 2000, 2005, 2007, 2008 and 2010. Neutral years are 1980, 1981, 1985, 1989, 1990, 1992, 1993, 1996, 2001 and 2003

TC genesis densities were calculated for these combinations of years. A smoothed density was generated from genesis points using a Gaussian-shaped symmetric fourth order polynomial kernel with a 2 grid point cutoff (approx 500km) to reduce noise between tracks. These densities were then normalised to remove differences in the number of storms detected, allowing a more direct comparison between the models and tracking schemes. TC genesis density composites are also generated for the Southern Hemisphere best track dataset (Kuleshov et al., 2010) ('observed TCs').

For the ensemble mean vorticity and wind shear fields, the correlation coefficient with the corresponding quantity at each grid point in the NCEP reanalysis was calculated, using three monthly mean values from model and reanalysis respectively.

\section{RESULTS}

Figure 1 shows the genesis density composites for observed TCs. The four panels from top to bottom show all years, El Niño years, La Niña years, Neutral years, and the difference between El Niño and La Niña years. The features of most interest are 1) the northward shift of genesis location in El Niño years in the south-western Pacific, 2) increased TC genesis on the northern coast of Western Australia, and in the eastern Indian ocean in La Niña years, and 3) increased genesis in El Niño years to the north of Madagascar.

Figures 2 and 3 show TC genesis densities for the two prediction systems and two tracking schemes. Despite the applied smoothing, the density field based on the observed tracks is less smooth than the model density fields, because there are at least ten realisations of each model, while only a single reality has been studied. The lowest panels of Figures 2 and 3 show that the main differences in TC density between El Niño and La Niña years in the observations are reproduced by the prediction systems. The northward shift of south Pacific TC activity in El Niño years is present in both models and captured by both tracking schemes. The region of increased cyclogensis near the north-western Australian coast in La Niña years is present in both models but is displaced northward compared to observations. In La Niña and Neutral years, the GCMs show a greater extension towards the east Pacific of the genesis densities than in observations. POAMA-M24 shows a north-east inclination for the genesis densities in the Indian Ocean, especially in OWZP tracking scheme. The JMA/MRI-CGCM overestimates the increased genesis in El Niño years to the north of Madagascar in both tracking schemes. There are errors in the registration of some features, for example in the Coral Sea, the region of increased cyclogenesis in El Niño years lies further south in the observations than in either model.

Figures 4 and 5 show the correlation coefficients between the model hindcasts and the corresponding reanalysis for 850 to $200 \mathrm{hPa}$ wind shear and $850 \mathrm{hPa}$ vorticity respectively. Shading is such that the blue colouring indicates correlations greater than 0.3 , which are considered statistically significant given the sample of 30 years. Top panels show the correlation skill for forecasts of November-December-January (NDJ) for outlooks initialised on November 1. Lower panels show the correlation skill for February-March-April (FMA) for the same initialisation time. The FMA forecasts are at a much longer lead time and so are expected to be less skillful. It is notable that the predictability of wind shear is relatively high in the region of the West Australian coast where cyclogenesis is concentrated. A region of low wind shear correlation in the north-eastern Australia region is present for both models. The predictability of seasonal mean $850 \mathrm{hPa}$ vorticity is comparatively low, but still high in regions on the Northern and Southern flanks of the South Pacific Convergence Zone (SPCZ), and off the coast of Western Australia. As with wind shear, the predictability of vorticity in northern Australia is quite low.

\section{DISCUSSION}

The OWZP tracking scheme does not detect many TCs in the Gulf of Carpentaria, while in the observations and in the traditional tracking scheme the region of TC genesis is more or less continuous along the Southern flank of the monsoon trough (below approximately $10^{\circ} \mathrm{S}$ ) and SPCZ (Vincent et al., 2009). One reason for this may be the short lived nature of systems in this region, another may be the lack of a sufficient number of ocean grid points in the coarse resolution models.

Due to the importance of vorticity and shear as local environmental parameters (Ramsay et al., 2008), we have analysed those fields to assess the models' ability to accurately predict anomalies in the environment in which TCs form. Information about the skill with which the GCMs forecast the fields used for tracking is used to determine confidence in the model tracks, and to gain insight into performance issues in particular regions. 
a) JMAOWZ

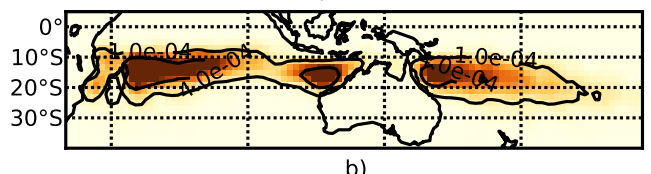

b)

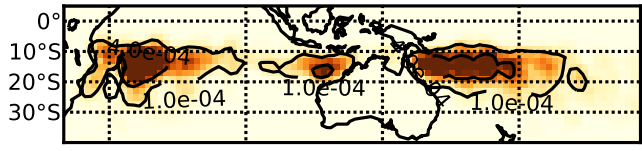

c)

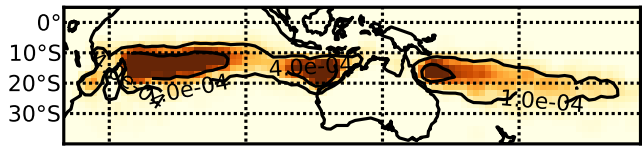

d)

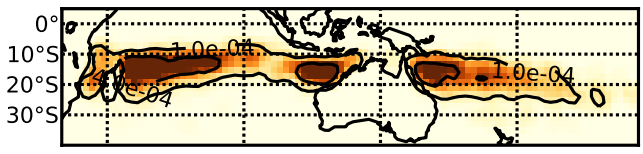

e)

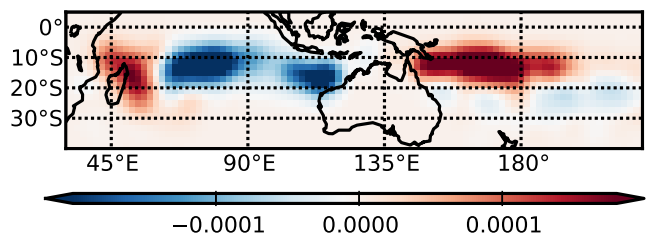

a) JMATK

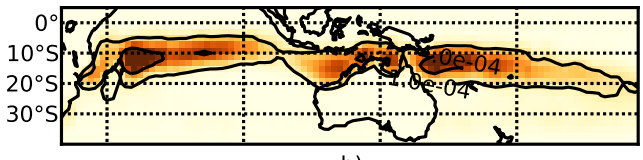

b)

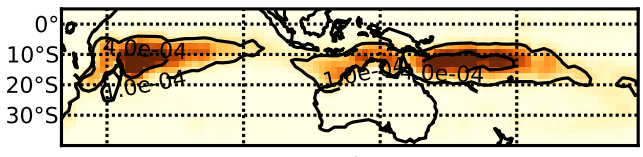

c)

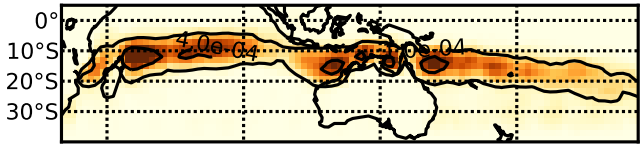

d)
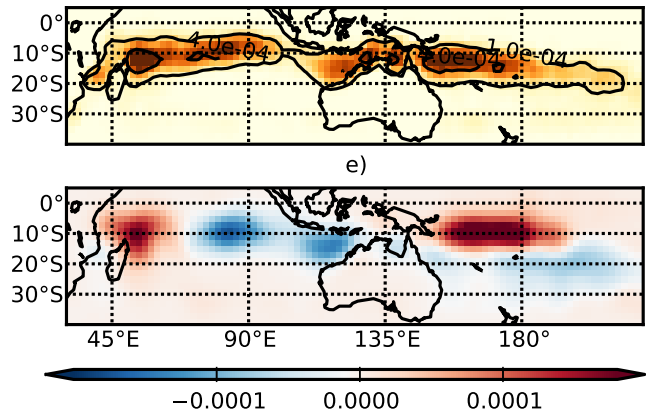

Figure 2. Tropical cyclone genesis densities for the JMA-MRI/CGCM. Left: OWZP tracking scheme. Right: traditional tracking scheme. Panels as for Figure 1.

The predictability of seasonal mean wind shear is quite high, and does not degrade as quickly with time as for other atmospheric variables such as rainfall. This might be expected due to the larger spatial and temporal scales of its variability. The relatively low model skill at forecasting wind shear and vorticity in the North Queensland region will limit the skill with which interannual variability in TC tracks can be forecast.

Using two operational seasonal forecasting GCMs and two TC tracking schemes we have demonstrated that the main features of observed variability between ENSO phases are reproduced. As ENSO represents the main source of interannual predictability, this is an important milestone in the development of operational TC seasonal predictions using dynamical models. We can expect GCM-based forecasts of TC genesis to be skillful for years in which ENSO has a strong influence on the pattern of cyclogenesis.

\section{ACKNOWLEDGEMENT}

The research discussed in this paper was conducted with the support of the Pacific Australia Climate Change Science and Adaptation Planning Program, a program supported by AusAID, in collaboration with the Department of Climate Change and Energy Efficiency, and delivered by the Bureau of Meteorology and the Commonwealth Scientific and Industrial Research Organisation (CSIRO).

\section{REFERENCES}

Diamond, H. J., A. M. Lorrey, and J. A. Renwick (2013, January). A southwest Pacific tropical cyclone climatology and linkages to the El Niño-Southern Oscillation. Journal of Climate 26(1), 3-25.

Dowdy, A. J., L. Qi, D. Jones, H. Ramsay, R. Fawcett, and Y. Kuleshov (2012, September). Tropical cyclone climatology of the south Pacific ocean and its relationship to El Niño-Southern oscillation. Journal of Climate 25(18), 6108-6122.

Kuleshov, Y., F. Chane Ming, L. Qi, I. Chouaibou, C. Hoareau, and F. Roux (2009, June). Tropical cyclone genesis in the southern hemisphere and its relationship with the ENSO. Ann. Geophys. 27(6), 2523-2538. 
a) POAMAOWZ

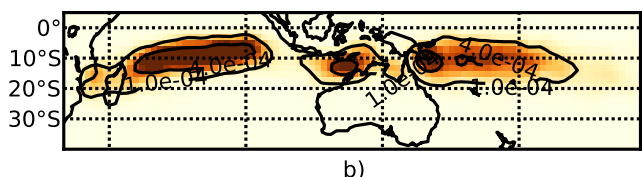

b)

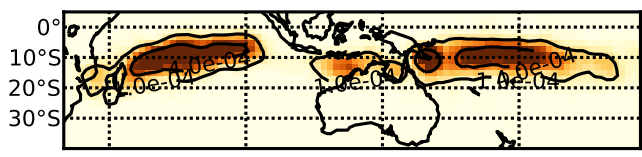

c)

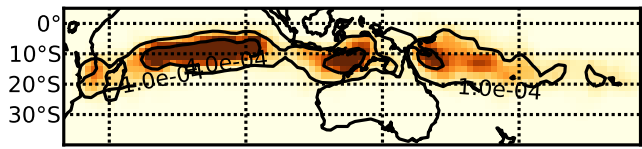

d)

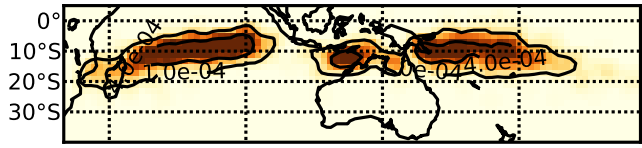

e)

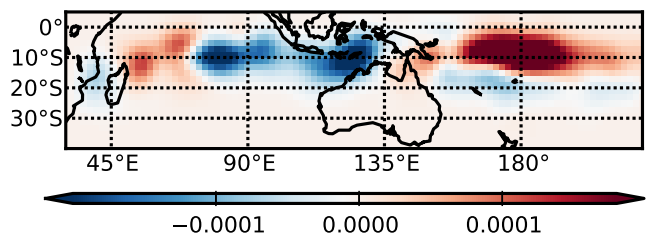

a) POAMATK

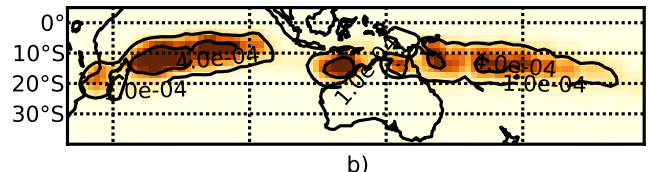

b)

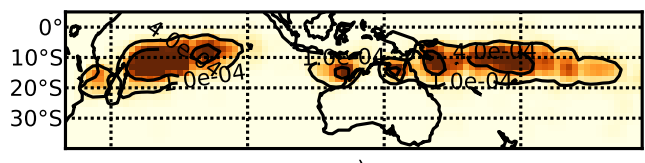

c)

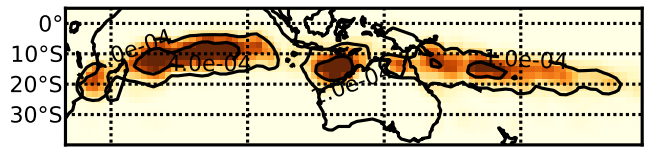

d)
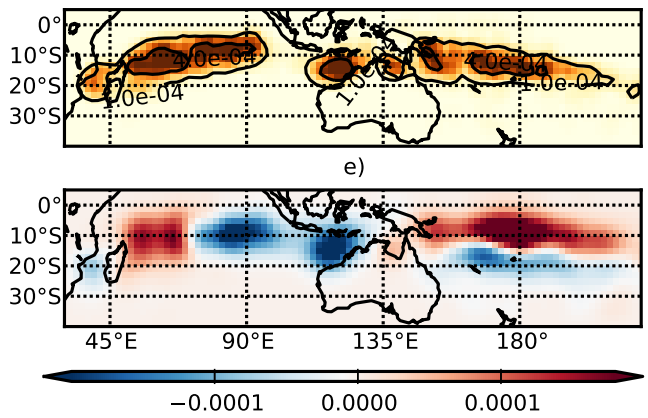

Figure 3. Tropical cyclone genesis densities for POAMA-M24. Left: OWZP tracking scheme. Right: Traditional tracking scheme. Panels labelled as for Figure 1.

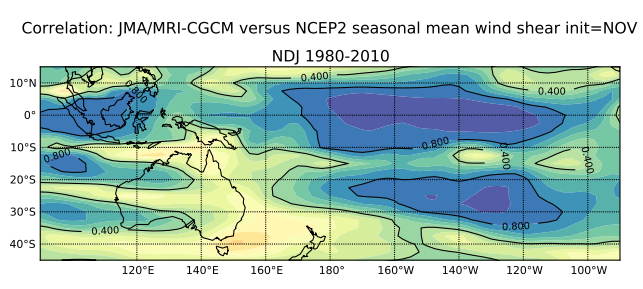

FMA 1981-2011

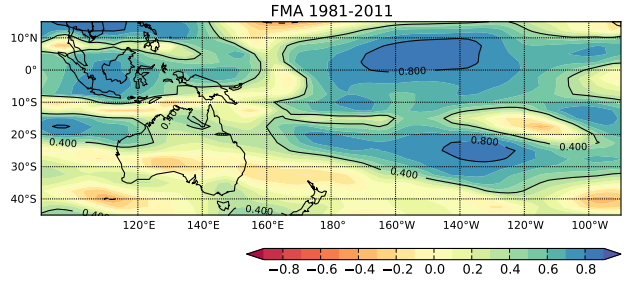

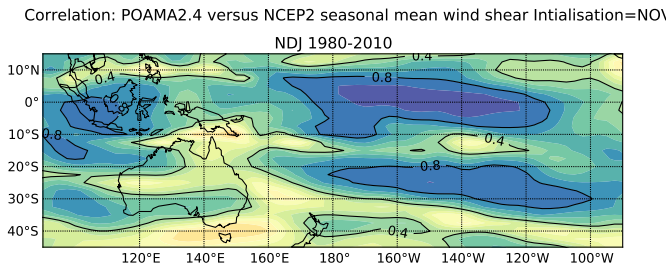

FMA 1981-2011

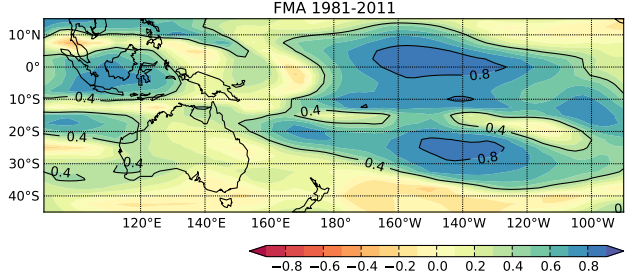

Figure 4. Correlation coefficient for interannual seasonal mean wind shear.

Kuleshov, Y., R. Fawcett, L. Qi, B. Trewin, D. Jones, J. McBride, and H. Ramsay (2010). Trends in tropical cyclones in the south Indian Ocean and the south Pacific Ocean. Journal of Geophysical Research: Atmospheres 115(D1), n/a-n/a.

Murakami, H. and M. Sugi (2010). Effect of model resolution on tropical cyclone climate projections. SOLA 6(0), 73-76.

National Meteorological and Oceanographic Centre (2013, March). Operational upgrade to Predictive Ocean Atmosphere Model for Australia (POAMA-M24). NMOC Operations Bulletin 96, Bureau of Meteorology. 
A. Charles et al, Prediction of Tropical Cyclone Activity with Coarse Resolution Global Climate Models
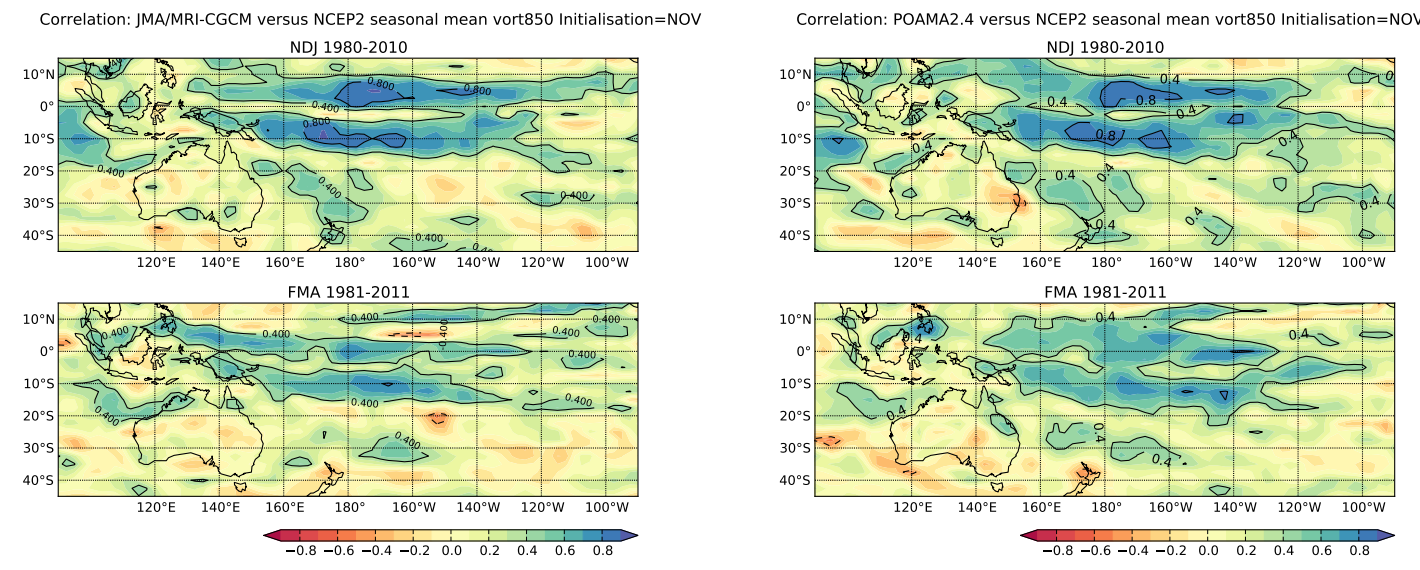

Figure 5. Correlation coefficient for interannual seasonal mean $850 \mathrm{hPa}$ vorticity.

Ramsay, H. A., L. M. Leslie, P. J. Lamb, M. B. Richman, and M. Leplastrier (2008, March). Interannual variability of tropical cyclones in the Australian region: Role of large-scale environment. Journal of Climate 21(5), 1083-1103.

Takaya, Y., T. Yasuda, T. Ose, and T. Nakaegawa (2010). Predictability of the mean location of typhoon formation in a seasonal prediction experiment with a coupled general circulation model. Journal of the Meteorological Society of Japan. Ser. II 88(5), 799-812.

Tory, K. J., S. S. Chand, R. A. Dare, and J. L. McBride (2013, February). The development and assessment of a model-, grid- and basin-independent tropical cyclone detection scheme. Journal of Climate, 130206114111004.

Vincent, E. M., M. Lengaigne, C. E. Menkes, N. C. Jourdain, P. Marchesiello, and G. Madec (2009, December). Interannual variability of the South Pacific Convergence Zone and implications for tropical cyclone genesis. Climate Dynamics 36(9-10), 1881-1896.

Vitart, F., M. R. Huddleston, M. Déqué, D. Peake, T. N. Palmer, T. N. Stockdale, M. K. Davey, S. Ineson, and A. Weisheimer (2007, August). Dynamically-based seasonal forecasts of Atlantic tropical storm activity issued in June by EUROSIP. Geophysical Research Letters 34, 5 PP.

Vitart, F., A. Leroy, and M. C. Wheeler (2010, September). A comparison of dynamical and statistical predictions of weekly tropical cyclone activity in the southern hemisphere. Monthly Weather Review 138(9), 3671-3682.

Vitart, F. and T. N. Stockdale (2001, October). Seasonal forecasting of tropical storms using coupled GCM integrations. Monthly Weather Review 129(10), 2521-2537.

Walsh, K. J. E., M. Fiorino, C. W. Landsea, and K. L. McInnes (2007, May). Objectively determined resolution-dependent threshold criteria for the detection of tropical cyclones in climate models and reanalyses. Journal of Climate 20(10), 2307-2314.

Watterson, I. G., J. L. Evans, and B. F. Ryan (1995, December). Seasonal and interannual variability of tropical cyclogenesis: Diagnostics from large-scale fields. Journal of Climate 8(12), 3052-3066.

Yasuda, T., Y. Takaya, C. Kobayashi, M. Kamachi, H. Kamahori, and T. Ose (2007). Asian monsoon predictability in JMA/MRI seasonal forecast system. CLIVAR Exchanges 43, 18-24. 